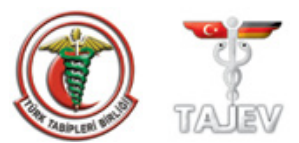

\title{
Inherited thrombophilia and reproductive disorders
}

\author{
Spyros A. Liatsikos ${ }^{1}$, Panagiotis Tsikouras ${ }^{1}$, Bachar Manav¹, Roland Csorba², Georg Friedrich von Tempelhoff ${ }^{2}$, \\ Georgios Galazios ${ }^{1}$ \\ ${ }^{1}$ Department of Obstetrics and Gynecology, Democritus University of Thrace, Greece \\ ${ }^{2}$ Department of Obstetrics and Gynecology, Clinicum Aschaffenburg, Teaching Hospital University of Würzburg, Germany
}

\section{Abstract}

Apart from its established role in the pathogenesis of venous thromboembolism (VTE), inherited thrombophilia has been proposed as a possible cause of pregnancy loss and vascular gestational complications. There is a lot of controversy in the literature on the relationship between inherited prothrombotic defects and these obstetric complications. This is a review of the literature on inherited thrombophilia and reproductive disorders. Factor V Leiden, prothrombin G20210A mutation, and protein S deficiency seem to be associated with late and recurrent early pregnancy loss, while their impact on other pregnancy complications is conflicting. No definite association has been established between protein $\mathrm{C}$ and antithrombin deficiency and adverse pregnancy outcome, primarily due to their low prevalence. Screening is suggested only for women with early recurrent loss or late pregnancy loss. Anticoagulant treatment during pregnancy should be considered for women with complications who were tested positive for thrombophilia. (J Turk Ger Gynecol Assoc 2016; 17: 45-50)

Keywords: Inherited thrombophilia, reproductive disorders, recurrent pregnancy loss

Received: 11 November, 2015

Accepted: 16 January, 2016

\section{Introduction}

Thrombophilia is a disorder caused by inherited and acquired defects and is defined as a predisposition to thrombosis (1). The most common cause of acquired thrombophilia is the antiphospholipid syndrome (APS). Inherited thrombophilia constitutes a group of abnormalities of blood coagulation, including the factor V Leiden mutation (FVL) (homozygous or heterozygous), the prothrombin (FII) G20210A mutation (Pm) (homozygous or heterozygous), and deficiencies of the endogenous anticoagulants, antithrombin (AT), protein $\mathrm{C}$, and protein S. Among these conditions, FVL and Pm are relatively common, while the others are rare. FVL is a point mutation (G1691A), resulting in an altered factor resistant to inactivation by protein $\mathrm{C}$. The Pm leads to a $20 \%-50 \%$ increase in plasma prothrombin levels $(2,3)$.

The prevalence of inherited thrombophilia in the general western population is estimated to be approximately $15 \%$ (4). However, it seems that there is a significant variation in the prevalence of these conditions among different geographical and tribal populations. FVL varies from $0.6 \%$ to $7.0 \%$, with the lowest frequency observed in Africa $(0 \%$ $0.6 \%)$ and the highest in Southern Europe (7\%). The mean prevalence in Northern Europe is 4\%. The prevalence of Pm varies from $0.2 \%$ to $3 \%$, being lowest in Africa ( $0 \%-0.3 \%$ ) and highest in Southern Europe (3\%). The mean value in Northern Europe is $2 \%$. Protein $\mathrm{C}$, protein $\mathrm{S}$, and AT deficiencies are extremely rare $(0.2 \%-0.4 \%, 0.03 \%-0.1 \%$, and $0.02 \%-0.2 \%$, respectively) (5).
The role of inherited thrombophilia in pregnancy loss and vascular gestational disorders has been investigated in several studies, and the results seem to be contradictory. The aim of this review was to elucidate the association of inherited thrombophilia and reproductive disorders. The value of screening women for inherited thrombophilia and the treatment options during pregnancy are also discussed.

\section{The association between inherited thrombophilia and reproductive disorders}

\section{Inherited thrombophilia and infertility}

Coulam et al. (6) reported that a prothrombotic tendency is associated with unexplained infertility, but this finding was not in agreement with data from Casadei et al. (7). To date, there has been no conclusive evidence in the literature to suggest an association of inherited thrombophilia and infertility other than recurrent implantation failure (8). Di Nisio et al. (9) conducted a systematic review and meta-analysis of all the available studies on the role of inherited thrombophilia in implantation failure. A significant association was found only for FVL [Odds ration (OR) 3.08; 95\% confidence interval (CI) 1.77-5.36].

\section{Inherited thrombophilia and recurrent pregnancy loss}

It is estimated that approximately $25 \%$ of conceptions and $15 \%$ of all clinically recognized pregnancies end in a miscarriage $(10,11)$. Moreover, three or more successive losses affect $1 \%-2 \%$ of women of reproductive age, and two or more successive losses affect approximately 5\% (12). Although several 
causes of recurrent pregnancy loss have been identified, 38\% of cases remain unexplained $(13,14)$. Thrombophilias have been suggested as a possible cause of recurrent miscarriage (RM) (15). The hypothesis that inherited thrombophilia may be associated with miscarriage was first investigated by the European prospective cohort of thrombophilia (EPCOT) (16). The authors observed an increased risk of pregnancy loss in 571 women with inherited thrombophilia (OR 1.35; 95\% CI 1.01-1.82).

In 2003, Rey et al. (16) conducted a meta-analysis of the data on the association of inherited thrombophilia and RM. They found a significant variability among studies in the definition of RM and the gestational period that miscarriage occurred. A significant association was identified for FVL, Pm, and protein S deficiency with non-recurrent and recurrent fetal loss. Protein $\mathrm{C}$ and AT deficiencies were not associated with RM; however, this result should not be considered conclusive because of their low prevalence in the general population.

A year later, Kovalevsky et al. (17) published the results of another meta-analysis, investigating the role of the two most common forms of inherited thrombophilia (FVL and Pm) in RM. The analysis reported significant among-study heterogeneity for FVL, but not for Pm. However, they did establish an association between FVL, Pm, and RM, with the carriers having a double risk for RM compared with women without thrombophilia. Finally, limiting the data to women with first-trimester recurrent pregnancy loss (RPL) appeared to weaken the association in the FVL analysis. Such an effect was not observed in the G20210A analysis.

The most recent and well-designed review on the association of inherited thrombophilia and RM was conducted by Rodger et al. (18) who reported an increased risk for miscarriage for women with FVL (OR 1.52; 95\% CI 1.06-2.19), but no association was found for Pm.

Although it appears that the results of the published studies are conflicting, most reviews suggest an association of RM with FVL and $\mathrm{Pm}$.

\section{Inherited thrombophilia and late pregnancy loss}

Kovalevsky et al. (17) also analyzed the association of inherited thrombophilia with loss at different stages of the pregnancy. Late loss was defined as a pregnancy being lost after its 13th week. They found that FVL was associated with early and late loss. Pm was associated with late loss and recurrent early loss but not isolated early loss. Protein S deficiency was also associated with late loss and early recurrent loss. AT and protein $\mathrm{C}$ deficiencies were not associated with pregnancy loss.

In a systematic meta-analysis (19) where late loss was defined as pregnancy loss after the $24^{\text {th }}$ week, there was a significant risk for early loss in homozygous FVL but a lower, non-significant risk in heterozygous FVL or Pm. With respect to late loss ( $3^{\text {rd }}$ trimester), there was a significant risk in heterozygous FVL and a lower, non-significant risk in heterozygous Pm. Although there was a higher risk for late loss in women with protein $\mathrm{S}$ deficiency, no such increase in risk was found for protein $\mathrm{C}$ and AT deficiency for early or late loss. Inherited AT deficiency which occurs in two forms (Type I: low antigen concentrations and activity; Type II: normal antigen concentrations, low activity) is associated with an increased risk of VTE and adverse pregnancy outcome as well (20). Type II AT deficiency associated with a defect at the heparin binding site (HBS) due to Leu99Phe mutation is a subtype that in its heterozygous form represents a minor risk for thrombosis, while homozygous carriers are prone to a high risk for early onset of arterial and venous thrombosis and pregnancy loss, despite anticoagulation with heparin (20). Overall, it seems that FVL and Pm are more strongly associated with late loss ( $2^{\text {nd }}$ and $3^{\text {rd }}$ trimester) than early loss $\left(1^{\text {st }}\right.$ trimester), whereas protein $\mathrm{S}$ deficiency seems to be significantly associated only with late loss.

\section{Inherited thrombophilia and pre-eclampsia}

A number of small studies have investigated the contribution of thrombophilia in the pathogenesis of pre-eclampsia $(2,21,22)$. Mello et al. (23) conducted a large multicenter case-control study to assess the prevalence of thrombophilic defects in women with severe and mild pre-eclampsia. There was a significant association between Pm with mild or severe pre-eclampsia and FVL with severe pre-eclampsia. There was no relationship between protein $\mathrm{C}$, protein $\mathrm{S}$, and AT deficiency with pre-eclampsia, but the number of the subjects with such defects was too small to allow for definite conclusions. Moreover, a significant increase was reported in the incidence of early onset of pre-eclampsia ( $<28$ weeks gestation) and disseminated intravascular coagulation [but not of hemolysis elevated liver enzymes low platelets (HELLP) syndrome, eclampsia, and pulmonary edema] in women with thrombophilia compared with the controls (23).

However, the most recent meta-analysis of Rodger et al. (18) did not observe any significant association between FVL and Pm with pre-eclampsia. Facchinetti et al. (24) studied the risk of recurrence of pre-eclampsia as well as the perinatal outcome following pre-eclampsia according to the presence or absence of thrombophilia in the mother. The rate of recurrence was $51.9 \%$ in women with inherited thrombophilia compared with only $25.9 \%$ in women without thrombophilia.

\section{Inherited thrombophilia and intrauterine growth retardation (IUGR)}

Wu et al. (19) found that embryos from homozygous FVL and heterozygous Pm mothers had an increased risk for IUGR. None of the other inherited prothrombotic defects were associated with IUGR in that study. Rodger et al. (18) failed to confirm the results by $\mathrm{Wu}$ et al. (19) because they reported no significant risk for IUGR in women tested positive for FVL or Pm.

\section{Inherited thrombophilia and placental abruption}

Wu et al. (19) reported a significant risk for placental abruption in pregnant women heterozygous for FVL (OR 4.70; 95\% CI 1.13-19.59) or Pm (OR 7.71; 95\% CI 3.01-19.76). This result however was questioned in the meta-analysis by Rodger et al. (18) who found no significant risk for placental abruption in women with FVL or Pm.

\section{Inherited thrombophilia and VTE}

It is well known that pregnancy is a thrombogenic condition, and the risk for VTE (deep venous thrombosis or pulmonary embolism) is significantly increased when additional prothrombotic factors coexist. The prevalence for VTE is gradually 
Table 1. Association between different types of inherited thrombophilia with pregnancy loss and a variety of pregnancy complications

\begin{tabular}{|c|c|c|c|c|c|}
\hline & FVL & Pm & Prot C def. & Prot S def. & AT def. \\
\hline Recurrent $1^{\text {st }}$ trimester loss $(\geq 3)$ & + & + & 0 & 0 & 0 \\
\hline Pre-eclampsia & $-/+$ & $-/+$ & 0 & 0 & 0 \\
\hline IUGR & $-/+$ & $-/+$ & 0 & 0 & 0 \\
\hline VTE & ++ & ++ & + & + & ++ \\
\hline & $\begin{array}{l}0 \\
- \\
-/+ \\
+ \\
++\end{array}$ & $\begin{array}{l}\text { Insufficient puk } \\
\text { No association } \\
\text { Published data } \\
\text { Weak associat } \\
\text { Strong associat }\end{array}$ & ry for an ass & & \\
\hline
\end{tabular}

increased from 1/1000 pregnancies (when no other prothrombotic conditions exist) to $1 / 500$ for heterozygous FVL women, 1/200 for heterozygous Pm, 4.6/100 for double heterozygous FVL/ Pm, 1/113 for protein C deficiency, and 1/2.8 for AT deficiency (5). According to the findings of Wu et al. (19), all inherited prothrombotic conditions significantly increased the risk for VTE. In summary, there is preliminary evidence to suggest that FVL and Pm are associated with second or third trimester loss, with insufficient evidence for the association with pre-eclampsia and IUGR. There is a need for larger, well-designed prospective trials. The association of different types of inherited thrombophilia and reproductive disorders is summarized in Table 1.

Is screening women for inherited thrombophilia prior to pregnancy necessary?

At present, there is no evidence to support universal screening for inherited thrombophilia prior to conception. Selective screening should be considered on the basis of family history of thrombosis or adverse reproductive history.

The National Society of Genetic Counselors in its guidelines for the genetic evaluation and counseling of couples with recurrent miscarriage adopted a more selective attitude for thrombophilia screening, including a personal or family history of VTE in its criteria. They suggested testing for FVL and Pm for all women with recurrent pregnancy loss. Until the results of further studies are published, testing for protein $\mathrm{C}$, protein $\mathrm{S}$, and AT deficiencies should be offered only to women with a personal/family history of VTE. Finally, full thrombophilia screening [AT, protein C, protein S, FVL mutation and APC Resistance Assay (APCR), Prothrombin Gene Mutation (G-20210-A, Lupus Anticoagulant (LA) and AntiCardiolipin antibodies (ACLA)] should be offered to women with RM and a common thrombophilic defect (FVL or Pm) diagnosed previously because the co-existence of another defect dramatically increases the risk for VTE and pregnancy complications $(25,26)$.

The American College of Obstetricians and Gynecologists (ACOG) did not recommend screening for inherited thrombophilia for women with a history of recurrent fetal loss or placental abruption because it is unclear whether anticoagulation treatment reduces the risk of recurrence. There is also insufficient evidence to support screening for thrombophilias in women with a history of IUGR or pre-eclampsia (27).

The Royal College of Obstetricians and Gynaecologists (RCOG) however recommended screening for inherited thrombophilia for women with second-trimester miscarriage. Testing should include FVL, Pm, and protein S (28).

Although there is no universal agreement on screening for inherited thrombophilia in reproductive disorders, a proposed screening strategy is outlined in Table 2.

\section{Treatment}

Antithrombotic agents could potentially increase the live-birth rate of subsequent pregnancies in women with inherited thrombophilia and RM or late loss, but the results of the studies investigating their role in the management of these conditions are controversial.

The treatment of inherited thrombophilia associated with reproductive disorders is governed by two considerations. The first is the prevention of venous thrombosis during pregnancy, which itself is a hypercoagulable state. Some practitioners would offer heparin treatment shortly after a pregnancy has been confirmed, whereas others offer heparin treatment only in the third trimester or just post-partum. The second consideration relates to the beneficial effect of treatment on pregnancy outcome. In this situation, the treatment will need to be started at a specific time of the pregnancy to improve the desired outcome. For example, if the intention of treatment is to reduce 
Table 2. Recommendations on screening for inherited thrombophilia in women with a history of pregnancy loss and a variety of pregnancy complications

\begin{tabular}{|c|c|c|c|c|c|}
\hline & FVL & Pm & Prot $C$ def. & Prot S def. & AT def. \\
\hline Recurrent $1^{\text {st }}$ trimester loss $(\geq 3)$ & + & + & + & + & + \\
\hline $2^{\text {nd }}$ or $3^{\text {rd }}$ trimester loss & + & + & + & + & + \\
\hline Pre-eclampsia & $+(1)$ & $+(1)$ & - & - & - \\
\hline \multirow[t]{2}{*}{ VTE } & + & + & + & + & + \\
\hline & $\begin{array}{l}- \\
+\end{array}$ & $\begin{array}{l}\text { Screening not re } \\
\text { Screening recor } \\
\text { (1) In recurren } \\
\text { (2) After the ex }\end{array}$ & $\begin{array}{l}\text { ded } \\
\text {-onset } \\
\text { common ca }\end{array}$ & & \\
\hline
\end{tabular}

the risk of recurrent first trimester loss, the treatments need to be started as soon as a pregnancy has been confirmed. If the intention of treatment is to prevent late loss or to reduce late pregnancy complications such as pre-eclampsia or IUGR, then the treatment should be started in the second trimester. There is much debate however about the likely benefit of heparin treatment on the outcome. Based on data extrapolated from the observation of the association (described earlier), it seems reasonable to offer treatment with heparin to women with FVL and Pm with recurrent or late pregnancy loss.

According to the ACOG and RCOG guidelines, there was insufficient clinical evidence that prophylaxis with unfractioned heparin or low molecular weight heparin (LMWH) prevents recurrence in women who had experienced miscarriage or placental abruption or IUGR. Although ACOG strongly discouraged the administration of any anticoagulation treatment in such cases, RCOG suggested that heparin therapy during pregnancy improves the outcome of women with mid-trimester miscarriage associated with inherited thrombophilias $(27,28)$.

The use of antithrombotics in pregnancy has to be monitored and evaluated for safety. The possibility of these agents causing more harm than good in these patients cannot be excluded. In contrast to coumarin derivatives, unfractionated heparin and LMWH do not cross the placenta; therefore, they do not have the potential to cause fetal bleeding or teratogenicity (29). Potentially serious maternal risks associated with heparin include bleeding, heparininduced osteopenia, and heparin-induced thrombocytopenia. These risks are greater for unfractionated than LMWH.

Kaandorp et al. (30) compared the risk for maternal and neonatal adverse events between pregnant women who did not receive any anticoagulation treatment with those who received aspirin only or aspirin plus nadroparin. No significant increase in the risk of serious maternal complications or neonatal problems was observed. However, minor side effects, such as bruising and swelling or itching at the injection site were more com- mon in women who received treatment. Similar results were reported in the Scottish Pregnancy Intervention (SPIN) trial (31). LMWH is as effective and safe as unfractionated heparin, with potential advantages in pregnancy, because it is less associated with thrombocytopenia and osteoporosis and it can be administered once daily (longer half-life). Low dose aspirin (less than $150 \mathrm{mg} /$ day) also appears to be safe, while the safety of higher doses of aspirin during the first trimester is uncertain $(29,32)$.

In a multicenter randomized control trial (RCT), 139 pregnant women with inherited thrombophilia without antiphospholipid antibodies at $<12$ weeks of gestation were recruited from all university hospitals in the Netherlands, two university hospitals in Australia, and one university hospital in Sweden as well as from six non university/teaching hospitals in the Netherlands between December 2000 and 2009. Either daily LMWH (dalteparin, $5000 \mathrm{IU}$ weight adjusted dosage) with aspirin $80 \mathrm{mg}$ or aspirin $80 \mathrm{mg}$ alone were administrated. According to the results of this trial, named FRUIT, adding LMWH to aspirin before 12 weeks gestation seems to reduce recurrent hypertensive disorders (HD) in women with previous early-onset HD and/or small for gestational age (SGA) in the context of an inheritable thrombophilia without antiphospholipid antibodies (33).

Between February 2000 and September 2012, the Thrombophilia in Pregnancy Prophylaxis Study (TIPPS) was conducted in 36 tertiary care centers in Canada, Australia, the USA, the UK, and France. In this open label randomized trial, 289 pregnant women with thrombophilia who were at an increased risk of placentamediated pregnancy complications, venous thromboembolism, or both were included. Women received either antepartum dalteparin 5000 international units (IU) once daily by subcutaneous self-injection from the day of randomization until 20 weeks of gestation followed by 5000 IU twice daily from 20 weeks until at least 37 weeks gestational age or no antepartum dalteparin. Antepartum dalteparin was not found to reduce the risk of either pregnancy loss, venous thromboembolism, or placenta- 
Table 3. Recommendations on the treatment of pregnant women with inherited thrombophilia and a history of pregnancy loss or pregnancy complications

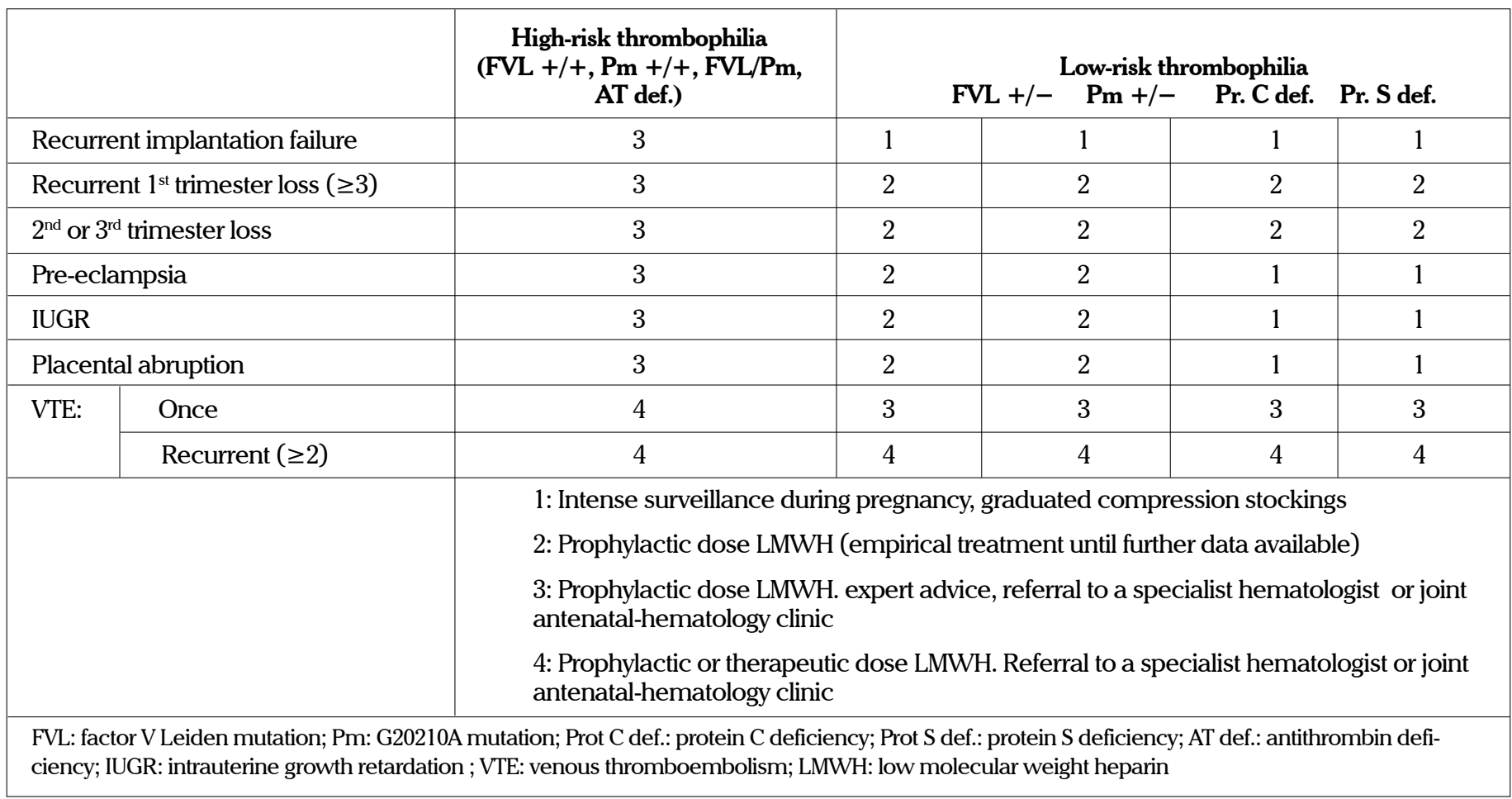

mediated pregnancy complications in pregnant women with thrombophilia [dalteparin 25/146 (17.1\%; 95\% CI 11.4\%-24.2\%) vs no dalteparin $27 / 143$ (18.9\%; 95\% CI 12.8\%-26.3\%); risk difference $-1.8 \%$ (95\% CI 10.6\%-7.1\%)]. This was the first large trial to show no benefit of LMWH administration in this high risk group of pregnant women. Moreover, researchers found that delteparin administration was associated with an increased risk of minor bleeding and noted LMWH administration complications. Lastly, a meta-analysis was conducted showing low evidence to support that LMWH might prevent recurrent severe placentamediated pregnancy complications (34).

As a conclusion, the use of LMWH and aspirin during pregnancy is considered safe, with only minor side effects.

\section{Should women with inherited thrombophilia be referred to a hematologist?}

Most general obstetricians and gynecologists today are familiar with common prothrombotic disorders, and they are capable of investigating and diagnosing common forms of thrombophilia. In addition, specialists in RM and high-risk pregnancies often have the skills to undertake the management of pregnant women with thrombophilia.

RCOG advises that the opinion of a local expert should be sought for women with AT deficiency, those with more than one thrombophilic defect, or those with additional risk factors. Women with AT deficiencies (particularly type 1 with reductions in both activity and antigen) have a high risk of recurrence and may require higher doses of LMWH or AT concentrate during pregnancy. They are also likely to be on long-term anticoagulation treatment with warfarin. Such conditions should be managed in collaboration with a hematologist expert in thrombosis (35).

The recommendations on the treatment of pregnant women diagnosed with sole or multiple thrombophilic defects in conjunction with a history of reproductive disorders are summarized in Table 3.

\section{Ongoing trials}

There are two ongoing RCTs investigating the efficacy and safe dose of LMWH in pregnancy (36).

The first one is The Highlow study (NCT Clinicaltrials.gov 01828697). It is an investigator-initiated, randomized-controlled, open-label trial that aims to provide high-quality evidence on the optimal prophylactic dose of LMWH in pregnancy in women with a history of VTE, comparing two different doses of LMWH (36).

The second one, the ALIFE2 study (NTR 3361) is an open-label trial, including women with inherited thrombophilia (FVL, Pm, AT deficiency, protein $\mathrm{C}$ deficiency, protein $\mathrm{S}$ deficiency, or a combination) and two or more miscarriages. The effect of LMWH (enoxaparin $40 \mathrm{mg}$ ) on live birth and on adverse pregnancy outcomes (e.g., pre-eclampsia, HELLP syndrome, intra-uterine growth restriction, placental abruption, premature delivery, and congenital malformations) and adverse effects of treatment (hemorrhagic episodes, thrombocytopenia, and allergic skin reactions to LMWH) are being studied (36).

\section{Conclusion}

FVL is associated with repeated implantation failure, RM, and late loss. Pm is associated with RM and late loss. Protein S defi- 
ciency is associated with late loss. There is insufficient evidence to suggest an association of other forms of inherited thrombophilia and reproductive disorders. Screening and treatment strategies based on the observed association seem reasonable, although there is as yet no firm evidence (such as RCTs) to confirm the benefits of treatment.

Ethics Committee Approval: N/A.

Informed Consent: N/A.

Peer-review: Externally peer-reviewed.

Author Contributions: Concept - P.T., S.A.L.; Design - P.T., S.A.L.; Supervision - G.G., G.F.V.T.; Funding - P.T., S.A.L.; Materials - P.T., S.A.L.; Data Collection and/or Processing - B.M., R.C.; Analysis and/or Interpretation - P.T., S.A.L.; Literature Review - B.M., R.C.; Writer-S.A.L., P.T.; Critical Review - S.A.L., P.T.; Other - G.F.V.T

Conflict of Interest: No conflict of interest was declared by the authors.

Financial Disclosure: The authors declared that this study has received no financial support.

\section{References}

1. Alonso A, Soto I, Urgellés MF, Corte JR, Rodríguez MJ, Pinto CR. Acquired and inherited thrombophilia in women with unexplained fetal losses. Am J Obstet Gynecol 2002; 187: 1337-42. [CrossRef]

2. von Tempelhoff GF, Schelkunov O, Demirhan A, Tsikouras P, Rath $\mathrm{W}$, Velten E, et al. Thrombelastometric results and platelet function during pregnancy in women receiving low molecular weight heparin with a history of recurrent/late abortion -A retrospective analysis. Clin Hemorheol Microcirc 2015; 61: 99-110. [CrossRef]

3. Tempelhoff GV, Schelkunov O, Demirhan A, Tsikouras P, Rath W, Velten E, et al. Correlation between blood rheological properties and red blood cell Indices ( $\mathrm{MCH}, \mathrm{MCV}, \mathrm{MCHC})$ in healthy women. Clin Hemorheol Microcirc 2015 (ahead of print).

4. Greer IA. Inherited thrombophilia and venous thromboembolism. Best Pract Res Clin Obstet Gynaecol 2003; 17: 413-25. [CrossRef]

5. Benedetto C, Marozio L, Tavella AM, Salton L, Grivon S, Di Giampaolo F. Coagulation disorders in pregnancy: acquired and inherited thrombophilias. Ann N Y Acad Sci 2010; 1205: 106-17. [CrossRef]

6. Coulam CB, Jeyendran RS. Thrombophilic gene polymorphisms are risk factors for unexplained infertility. Fertil Steril 2009; 91 (Suppl 4): 1516-7. [CrossRef]

7. Casadei L, Puca F, Privitera L, Zamaro V, Emidi E. Inherited thrombophilia in infertile women: implication in unexplained infertility. Fertil Steril 2010; 94: 755-7. [CrossRef]

8. Bianca S, Barrano B, Cutuli N, Indaco L, Cataliotti A, Milana G, et al. Unexplained infertility and inherited thrombophilia. Fertil Steril 2009; 92: e4. [CrossRef]

9. Di Nisio M, Rutjes AW, Ferrante N, Tiboni GM, Cuccurullo F, Porreca E. Thrombophilia and outcomes of assisted reproduction technologies: a systematic review and meta-analysis. Blood 2011; 118: 2670-8. [CrossRef]

10. Huisjes HJ. Continuing increase in the number of extrauterine pregnancies. Ned Tijdschr Geneeskd 1984; 128: 1285-6.

11. Everett $C$. Incidence and outcome of bleeding before the 20th week of pregnancy: prospective study from general practice. BMJ 1997; 315: 32-4. [CrossRef]

12. Greer IA. Thrombophilia: implications for pregnancy outcome. Thromb Res 2003; 109: 73-81. [CrossRef]

13. Jivraj S, Anstie B, Cheong YC, Fairlie FM, Laird SM, Li TC. Obstetric and neonatal outcome in women with a history of recurrent miscarriage: a cohort study. Hum Reprod 2001; 16: 102-6. [CrossRef]

14. Li TC, Makris M, Tomsu M, Tuckerman E, Laird S. Recurrent miscarriage: aetiology, management and prognosis. Hum Reprod Update 2002; 8: 463-81. [CrossRef]
15. Preston FE, Rosendaal FR, Walker ID, Briët E, Berntorp E, Conard J, et al. Increased fetal loss in women with heritable thrombophilia. Lancet 1996; 348: 913-6. [CrossRef]

16. Rey E, Kahn SR, David M, Shrier I. Thrombophilic disorders and fetal loss: a meta-analysis. Lancet 2003; 361: 901-8. [CrossRef]

17. Kovalevsky G, Gracia CR, Berlin JA, Sammel MD, Barnhart KT. Evaluation of the association between hereditary thrombophilias and recurrent pregnancy loss: a meta-analysis. Arch Intern Med 2004; 164: 558-63. [CrossRef]

18. Rodger MA, Betancourt MT, Clark P, Lindqvist PG, Dizon-Townson $\mathrm{D}$, Said J, et al. The association of factor V leiden and prothrombin gene mutation and placenta-mediated pregnancy complications: a systematic review and meta-analysis of prospective cohort studies. PLoS Med 2010; 7: e1000292. [CrossRef]

19. Wu O, Robertson L, Twaddle S, Lowe GD, Clark P, Greaves M, et al. Screening for thrombophilia in high-risk situations: systematic review and cost-effectiveness analysis. The Thrombosis: Risk and Economic Assessment of Thrombophilia Screening(TREATS) study. Health Technol Assess 2006; 10: 1-110. [CrossRef]

20. Kovac M, Mitic G, Miljic P, Mikovic Z, Mandic V, Djordjevic V, et al. Poor pregnancy outcome in women with homozygous type-II HBS antithrombin deficiency. Thromb Res 2014; 133: 1158-60. [CrossRef]

21. von Tempelhoff GF, Tsikouras P, Rath W, Velten E, Csorba R. Rheological, hemostaseological changes during immunetherapy for prevention of HELLP-syndrome in a patient with elevated phospholipid antibodies. Clin Hemorheol Microcirc 2015; 60: 123-31. [CrossRef]

22. Csorba R, Yilmaz A, Tsikouras P, Wieg C, Teichmann A, von Tempelhoff GF. Rheological parameters in the umbilical cord blood in moderate and severe forms of preeclampsia. Clin Hemorheol Microcirc 2013; 55: 391-401.

23. Mello G, Parretti E, Marozio L, Pizzi C, Lojacono A, Frusca T, et al. Thrombophilia is significantly associated with severe preeclampsia: results of a large-scale, case-controlled study. Hypertension 2005; 46: 1270-4. [CrossRef]

24. Facchinetti F, Marozio L, Frusca T, Grandone E, Venturini P, Tiscia $\mathrm{GL}$, et al. Maternal thrombophilia and the risk of recurrence of preeclampsia. Am J Obstet Gynecol 2009; 200: 46.e1-5. [CrossRef]

25. Laurino MY, Bennett RL, Saraiya DS, Baumeister L, Doyle DL, Leppig $\mathrm{K}$, et al. Genetic evaluation and counseling of couples with recurrent miscarriage: recommendations of the National Society of Genetic Counselors. J Genet Couns 2005; 14: 165-81. [CrossRef]

26. Baglin T1, Gray E, Greaves M, Hunt BJ, Keeling D, Machin S, et al. Clinical guidelines for testing for heritable thrombophilia. Br J Haematol 2010; 149: 209-20. [CrossRef]

27. ACOG Practice Bulletin No 124, September 2011.

28. RCOG Green-top Guideline No. 17, April 2011.

29. Ginsberg JA, Crowther MA, White RH, Ortel TL. Anticoagulation therapy. Hematology Am Soc Hematol Educ Program 2001: 339-57. [CrossRef]

30. Kaandorp SP, Goddijn M, van der Post JA, Hutten BA, Verhoeve HR, Hamulyák $\mathrm{K}$, et al. Aspirin plus heparin or aspirin alone in women with recurrent miscarriage. N Engl J Med 2010; 362: 1586-96. [CrossRef]

31. Clark P, Walker ID, Langhorne P, Crichton L, Thomson A, Greaves $\mathrm{M}$, et al. SPIN (Scottish Pregnancy Intervention) study: a multicenter, randomized controlled trial of low-molecular-weight heparin and low-dose aspirin in women with recurrent miscarriage. Blood 2010; 115: 4162-7. [CrossRef]

32. Sanson BJ, Büller H. Is there a role for thrombolytic therapy in venous thromboembolism? Haemostasis 1999; 29(Suppl 1): 81-3. [CrossRef]

33. de Vries JI1, van Pampus MG, Hague WM, Bezemer PD, Joosten $\mathrm{JH}$; FRUIT Investigators. Low-molecular weight heparin added to aspirin in the prevention of recurrent early-onset pre-eclampsia in women with inheritable thrombophilia: the FRUIT-RCT. J Thromb Haemost 2012; 10: 64-72. [CrossRef]

34. Rodger MA, Hague WM, Kingdom J, Kahn SR, Karovitch A, Sermer $\mathrm{M}$, et al. Antepartum dalteparin versus no antepartum dalteparin for the prevention of pregnancy complications in pregnant women with thrombophilia (TIPPS): a multinational open-label randomised trial. Lancet 2014; 384: 1673-83. [CrossRef]

35. RCOG Green-top Guideline No. 37a, 2009.

36. Middeldorp S. New studies of low-molecular-weight heparin in pregnancy. Thromb Res 2015; 135(Suppl 1): 26-9. [CrossRef] 